Article

\title{
Development of Green Ports with the Consideration of Coastal Wave Energy
}

\author{
Li Li, Jiadong Zhu, Guanqiong Ye and Xuehao Feng * \\ Ocean College, Zhejiang University, Zhoushan 316021, China; lilizju@zju.edu.cn (L.L.); \\ 21634084@zju.edu.cn (J.Z.); 0014138@zju.edu.cn (G.Y.) \\ * Correspondence: fengxuehao@zju.edu.cn; Tel.: + 86-158-5821-3431
}

Received: 24 October 2018; Accepted: 15 November 2018; Published: 19 November 2018

\begin{abstract}
Considering the rapid development of maritime logistics, the reduction of energy consumption at ports is important in the sustainable development of global economics. Oceans have been known as sources of clean energy, and wave energy is attracting more and more attention from both scholars and practitioners. Even though much effort has been made to develop advanced technologies of wave energy, it is still not clear how ports and electricity plants will evaluate its performance and make decisions on the investment. This paper analyzed the decision framework of ports and electricity plants that can decide how much to invest into wave energy converters, by considering the uncertainty of wave energy supply. A mathematical model is developed to obtain the optimal decisions of a single port and electricity plant for different cases. We show that in most cases, the port has a no lower motivation for investing in the wave energy than the electricity plant. Our theoretical analyses also shed light on the impacts of the parameters on the optimal decisions. Considering the difficulty in estimating the uncertainty of wave energy supply, we extend the distribution-free model to our problem which can make our model more practical.
\end{abstract}

Keywords: green port; wave energy; optimization; uncertainty; distribution-free model

\section{Introduction}

Greenhouse gas emissions are a serious problem in sustainability in the modern world. Meanwhile, with the development of globalization, maritime logistics has been more and more important in the international trade [1]. As key nodes in global supply chains, ports play an important role in not only productivity but also energy consumption. Governments and port authorities in many countries have proposed future plans of reducing greenhouse gas emission in port segments. For instance, the Ministry of Transport of China announced China's thirteenth five-year plan (from 2016 to 2020) about the target reduction of greenhouse gas emission. It proposes that compared with the year of 2015, both of the energy consumption per unit throughput and $\mathrm{CO}_{2}$ emission of ports in China should be respectively decreased by $2 \%$ until 2020. The energy consumption per unit turnover and $\mathrm{CO}_{2}$ emission of vessels in China should be respectively decreased by $6 \%$ and $7 \%$, compared with the year of 2015. Table 1 shows the detailed target of $\mathrm{CO}_{2}$ emission reduction in 2020 proposed by Ministry of Transport of China.

Generally speaking, there are two main types of sources of greenhouse gas emission at port segment. The first one is a direct source which results from the fuel oil used at ports, such as yard trucks, vessels, and other oil-consuming equipment. The second source is an indirect one related to the electricity. Many types of equipment such as the quay crane, yard crane, and Automated Guided Vehicle (also well known as AGV), are using electricity as the power. If the electricity is converted from coal, then consuming this type of electricity also leads to $\mathrm{CO}_{2}$ and $\mathrm{SO}_{2}$ emission. Therefore, many new approaches have been developed to reduce greenhouse gas emission on the 
side of energy supply for port and shipping, such as wind turbines, photovoltaics, wave energy, and foldable containers [2-4]. This practice could be more meaningful under the limitation of greenhouse gas emission set by International Maritime Organization.

Table 1. China's target of reducing $\mathrm{CO}_{2}$ emission in 2020 with the year of 2015 as a benchmark.

\begin{tabular}{ccc}
\hline Index & Industry & Expected Target in 2020 (\%) \\
\hline & Passenger Vehicle & -2.6 \\
& Truck & -8 \\
$\mathrm{CO}_{2}$ Emission & Vessel & -7 \\
& City Transport & -12.5 \\
& Port & -2 \\
\hline
\end{tabular}

Ocean energy could be one of the fruitful directions among the current renewable energy sources because of its huge amount of reserves, such as wave energy [5,6]. It is approximately estimated that the potential wave energy in the world is as high as 2 TW [7]. As one important type of ocean energy, wave energy is attracting more and more attention from not only academic but also commerce and society. Considering that it can be obtained from wave energy converters along coastlines, many people have the reason to believe that it has the potential to improve the sustainability of port operation and city development.

There are many studies on green port development. Acciaro et al. qualitatively discussed the role of port authorities in seaports' energy management with wind or wave as an example of sources of clean energy for seaports [8]. Chen and Pak proposed a Delphi evaluation framework to analyze the green performance of main ports in China, in which low-carbon and energy saving are considered as important indices [9]. Schipper et al. implemented a methodology to assess the efficiency and sustainability of port plans and the results illustrate that social and environmental factors should be combined with economy into a long-term plan [10]. Wan et al. developed an evaluation model to quantitatively measure the green port development, by using drivers, pressures, states, impacts, and responses as indices [11]. Chen and Lam implemented a two-stage data envelopment analysis method to evaluate the sustainability of ports based on the relationship between ports and cities [12]. Vaio et al. focused on the decision-making process of port authorities and investigated the key performance indicators with the consideration of sustainability [13]. See Shi et al. [14] for a detailed review of the themes and methods in the research evolution of green shipping [14].

Even though the wave energy technology has not been widely implemented as a commercial operation, there are a large number of scholars and research institutes who conducted various designs of wave energy converters or developed new analytical models [15-21]. However, the economic analysis of the wave energy and operational decisions of energy suppliers and consumers (e.g., electricity plant and ports) have rarely been touched upon. In this paper, we consider an electricity supply chain with a single port (she) and a single electricity plant (he). Supply chain members can decide how much to invest into wave energy converters to get electricity with the aim of maximize their own profits. We attempted to answer the following questions.

(i) What are the optimal decisions of the port and electricity plant when they have to decide on the investment in wave energy converters under uncertain wave energy supply, and who is more incentivized to invest?

(ii) How parameters influence the optimal decisions of supply chain members and how government (or authority) can encourage them to implement wave energy?

(iii) What is an efficient decision approach when the distribution of wave energy supply is not fully known?

Based on the characteristics of wave energy, we develop a model by considering the electricity generated from wave energy as a newsvendor-type product. Newsvendor-type product is a classic type of product with some unique characteristics. First, managers usually have a single opportunity 
to make a decision for this product in a period due to the long lead-time of supply [22]. For instance, it is not easy for a newsvendor to buy newspapers from the publisher in the afternoon when the former finds a stock out. The port or electricity plant managers may also find difficulty in getting more wave energy capacity in a short time by expanding the wave energy converters, because the construction could be relatively time consuming. Second, the demand of newsvendor-type product is usually uncertain. For example, toggeries may fail to exactly estimate the demand of cloths of a certain style in one season in advance. Even though the port's electricity demand could be known, the wave energy supply is relatively uncertain because of the dynamic natural conditions and global climate change. Even though numerical models have been developed to estimate the wave condition, it still could be worthwhile investigating the optimal investment decision under uncertain wave supply. The first reason is that predicting the amount of wave supply in a long-term (such as one year) within a small range of error usually requires a comprehensive data collection in long history. This work could be unavailable for many developing countries who attempt to build new ports. The second reason is that error is quite difficult to eliminate in the prediction for specific coastlines of ports. Even though the error can be limited within a range, making decisions to maximize the expected profit by considering the uncertainty of wave supply could be more appropriate in some cases than making decisions by using an exact amount of wave supply obtained from the prediction. We show that this supply uncertainty makes the wave energy share the same modeling logic of newsvendor-type products (see Section 3). Third, the essential problem in newsvendor-type product is the phenomenon of double marginalization that results from the difference between supplier's production cost and wholesale price charged for the retailer. Because the wholesale price is higher than the supplier's production cost, the retailer's optimal order quantity under the decentralized control is lower than the supply-chain-wide optimal order quantity [23-25]. Our study also illustrates that the motivations of the port and electricity plant on investing in wave energy converters vary due to the difference between price and production cost of electricity.

The remaining paper is organized as follows. Motivation and challenges of implementing wave energy converters are discussed in Section 2. Section 3 proposes the mathematical model and developed optimal decisions under different cases. In the same section, that model is extended to distribution-free model to show how to make good decisions when the information of wave energy supply is partially available. Section 4 illustrates the model and findings with a numerical experiment. Managerial insights on policies of encouraging green ports are discussed in Section 5. We summarize the concluding remarks and suggest future research directions in Section 6.

\section{Motivation and Challenges of Wave Energy Implementation}

\subsection{Motivation for Implementation of Wave Energy}

Considering the large and increasing numbers of ports and containers in the world, we may conjecture that the greenhouse gas emission would be more serious if this traditional type of electricity remains common. Without a doubt, it can bring high challenges to the sustainability of ports and shipping. The second disadvantage of traditional electricity of seaports is the uncertainly of the market price of coal according to the world-wide demand and supply. This price may further influence the price of electricity that results in uncertainty of cost for ports. In addition, because more and more mega-vessels are involved in the current shipping industry, deep-water ports are becoming popular. Many deep-water ports are located on islands due to the geographical condition, such as several container and cargo terminals of Shanghai and Ningbo-Zhoushan port. Hence, it would not be beneficial to build a traditional electricity plant on an isolated island for port with the consideration of economy of scale and the transportation cost of materials from the mainland to the port, e.g., coal.

In contrast with the above disadvantages of traditional electricity, the wave energy has its specific characteristics which could be interesting to port managers and governments. Because the converters generate electricity by using the movement of wave, this process does not discharge greenhouse 
gas. Moreover, this process requires no materials like coal. Hence, the cost is relatively certain and independent of the exogenous prices of materials. Considering that wave energy acts as the material, the converters might have plenty of materials along some coastlines. Hence, there might exist ports near which the wave energy supply is considerable. In addition, generally speaking, the electricity price is increasing due to the development of economics and higher electricity demand. For example, it is reported that the average price of electricity in China (unit: CNY per KWh) has been increased from 0.54 in July 2003 to 0.79 in the same month in 2013 [26]. As a consequence, we can conjecture that wave energy could be more competitive when the economy is developing and the price of traditional electricity increases.

\subsection{Challenge}

Without any doubt, there exist limitations and challenges of the implementation of wave energy converters; otherwise they should have been ubiquitous at ports. Uihlein and Magagna conducted a comprehensive review on the current state of research in wave and tidal current energy [27]. Several challenges of implementing wave energy are uncovered in that study. For instance, it would be important to improve the resource assessment to reduce uncertainties about amiable resources which can make investors more confident in wave energy. While more and more sophisticated models on wave resource assessment are developed, a harmonization of approaches are still missing. From the views of economy and sustainability, we summarize the following three main challenges.

First, the investment in implementing the wave energy converters could be higher than the traditional electricity in current days. One reason is that the technology of the wave energy converters is new. The second reason is the converters' construction condition is along the coastline line and partially underwater, which is much more complicated than hinterland. In addition, the fixed cost of this implementation can also be high due to the preliminary investigation into the wave condition, construction of infrastructure, staff training, and so on. This high investment leads to high average cost of wave energy that may make small ports or electricity plants hesitate to invest in wave energy converters.

Second, uncertainty of wave supply can make the decisions on investment complex and the expected benefit of wave energy unclear. For one thing, exactly estimating the wave condition in future can be quite challenging. Managers may have difficulty in deciding the optimal capacity of wave energy converters when the exact amount of wave supply is unknown. Moreover, the decisions sometimes require some information of the uncertain wave supply, such as the distribution of wave supply in one year. It could be time consuming and costly to collect the information, and in some cases this information would be unavailable due to the natural condition.

Third, how can governments (or authority) encourage the implementation of wave energy involves a long list of potential polices. Prior to making policies, governments should understand how wave-energy electricity impacts the benefits of ports and electricity plants. Different organizations can have different levels of preference for this new type of electricity. In addition, governments need to compare the performance of different policies, such as encouraging the port to sell surplus electricity to the grid, increasing the price of traditional electricity, charging the electricity plant a penalty fee for traditional electricity, and so on. All these questions may require an analytical study to get the optimal solutions.

\section{Model Formulation and Analysis}

\subsection{Mathematical Formulation}

We consider electricity management problem consisting of a seaport and an electricity plant. The port has a fixed service demand for a time period.

Because the converter converts the wave energy to electricity with the natural wave energy, we assume that the material cost for the wave energy is small and $c_{e}<c_{t}$. For a capacity of wave 
energy converters, we can obtain the corresponding $q$ based on $\eta$, that is $q=\eta Q$. Figure 1 illustrates the framework of the problem under consideration. Note that some flows may not be independent of others. When the port invests in wave energy converters, she spends $c_{r} q / \eta+c_{e} \min \{q, X\}$ wherein $\min \{q, X\}$ is the amount of electricity generated by the converters (Flows (1) and (2)). If there is surplus electricity from Flow (1), then the port can sell it to the grid with a salvage value. Hence, Flows (3) and (4) cannot exist without the above two flows. If the electricity from Flow (1) cannot satisfy the port's demand, then the port has to purchase traditional electricity from the electricity plant at a price of $w$ (Flows (5) and (6). It means that Flows (5) and (6) cannot exist with Flows (3) and (4) simultaneously. When the electricity plant invests in wave energy converters, he may get wave-energy electricity, and sell it and traditional electricity to the port at a price of $w$ (Flows (5), (6), (7), and (8). Note that Flow (5) may contain both types of electricity. In addition, the plant can also sell surplus wave-energy electricity to the grid when he invests in the converters (Flows (9) and (10). Because we do not consider the case wherein the port and the electricity plant invest in wave energy converters simultaneously, Flows (1), (2), (3) and (4) cannot exist with Flows (7), (8), (9) and (10.
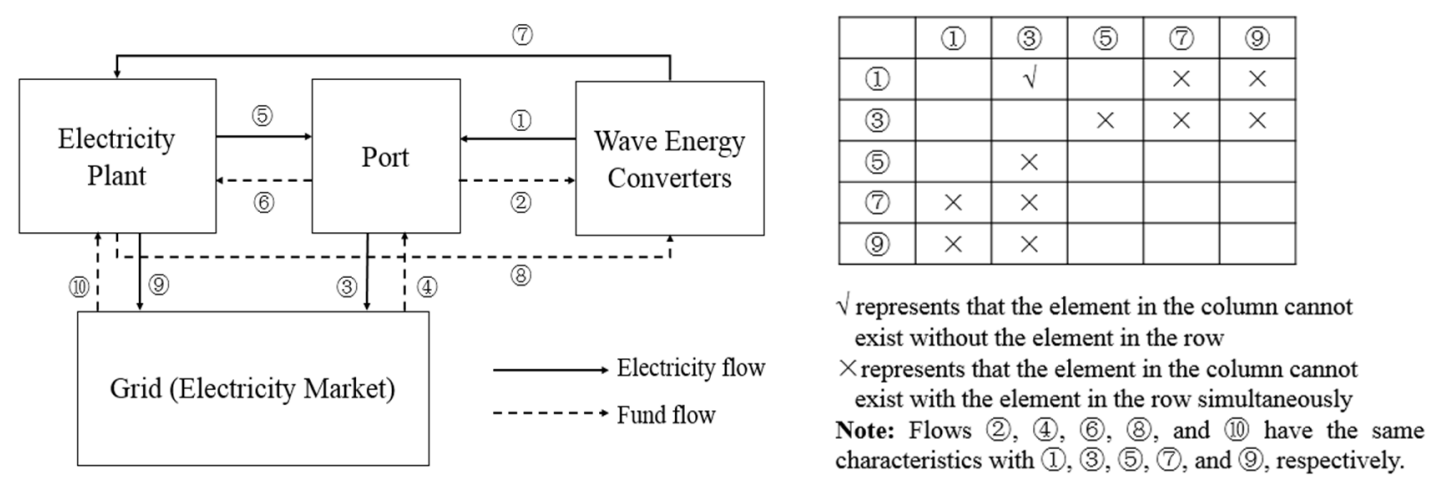

Figure 1. Framework of the problem.

\subsection{The Case Wherein the Port Invests in the Wave Energy Converters}

Because $q=\eta Q$, we can obtain the port's profit function with one decision variable, $q$. Let $\Pi_{p}(q \mid w)$ be the profit function of the port. If $q$ is no greater than $D / \beta$, then the port will always purchase a positive amount of electricity from the electricity plant. When there is no salvage value of the surplus electricity, the port cannot benefit from a $q$ higher than $D / \beta$. In this case, we can obtain the port's objective function as follows.

$$
\operatorname{Max} \Pi_{p}(q \mid w)=p D-c_{e} E \min (q, X)-c_{r} \frac{q}{\eta}-w\left(\frac{D}{\beta}-E \min (q, X)\right)
$$

s.t. $q \leq D / \beta$.

Let $q^{*}$ be the port's optimal $q$ to maximize her own expected profit.

Proposition 1. Suppose that the port invests in the wave energy converters and there is no salvage value for surplus electricity of the port.

(i) if $w \leq c_{r} / \eta+c_{e}$, then $q^{*}=0$.

(ii) $w>c_{r} / \eta+c_{e}$, the port's optimal $q$ satisfies

$$
q^{*}=\min \left\{\frac{D}{\beta}, F^{-1}\left(1-\frac{c_{r}}{\eta\left(w-c_{e}\right)}\right)\right\}
$$


Proof. (i) Without a doubt, $q$ should be no greater than $U$. When $q$ is higher than $L$, Objective Function (1) can be written as

$$
\begin{aligned}
& \Pi_{p}(q \mid w) \\
& =p D-c_{e}\left(\int_{L}^{q} x f(x) d x+\int_{q}^{U} q f(x) d x\right)-\frac{c_{r}}{\eta} q-w\left(\frac{D}{\beta}-\int_{L}^{q} x f(x) d x-\int_{q}^{U} q f(x) d x\right) \\
& =p D+\left(w-c_{e}\right)\left(\int_{L}^{q} x f(x) d x+\int_{q}^{U} q f(x) d x\right)-\frac{c_{r}}{\eta} q-w \frac{D}{\beta}
\end{aligned}
$$

with $q \leq D / \beta$. It is easy to show that $\frac{d \Pi_{p}(q \mid w)}{d q}=\left(w-c_{e}\right)(q f(q)+(1-F(q))-q f(q))-\frac{c_{r}}{\eta}$. Considering that $0 \leq F(q) \leq 1$ for any a $q \in[L, U]$, we can obtain that $d \Pi_{p}(q \mid w) / d p$ is always smaller than zero if $w-c_{e} \leq c_{r} / \eta$. In this case, $\Pi_{p}(q \mid w)$ is always decreasing with $q$ and then $q^{*}=L$. When $q$ is no greater than $L$, the expected amount of electricity generated from wave energy is equal to $q$. In this case, Objective Function (1) can be written as $\Pi_{p}(q \mid w)=p D+\left(w-c_{e}\right) q-c_{r} q / \eta-w D / \beta$. In this case, $q^{*}=0$ and $\Pi_{p}(0 \mid w)>\Pi_{p}(L \mid w)$ if $w \leq c_{r} / \eta+c_{e}$. Hence, we have $q^{*}=0$ if $w \leq c_{r} / \eta+c_{e}$.

(ii) Because there is no salvage value of the surplus electricity, we can find the optimal $q$ under Objective Function (1) with $q^{*} \leq D / \beta$. If $w \geq c_{r} / \eta+c_{e}$, then we have $w \geq c_{e}$ and $\frac{d^{2} \Pi_{p}(q \mid w)}{d q^{2}}=-\left(w-c_{e}\right)(f(q))<0$. Therefore, $\Pi_{p}(q \mid w)$ will achieve the maximum value with $q^{*}$ that satisfies $d \Pi_{p}\left(q^{*} \mid w\right) / d p=0$. By letting $d \Pi_{p}(q \mid w) / d p=0$, from Equation (3) we have $\left(w-c_{e}\right)(1-F(q))-c_{r} / \eta=0$. Hence, we can find that $\Pi_{p}(q \mid w)$ is increasing with $q$ within the range of $\left[L, F^{-1}\left(1-c_{r} / \eta /\left(w-c_{e}\right)\right)\right]$. According to the $\Pi_{p}(q \mid w)$ in the above proof when $q \leq L$, we can see that $\Pi_{p}(L \mid w)$ is greater than $\Pi_{p}(q \mid w)$ for any $q \leq L$ when $w \leq c_{r} / \eta+c_{e}$. Therefore, we have $\Pi_{p}\left(F^{-1}\left(1-c_{r} / \eta /\left(w-c_{e}\right)\right) \mid w\right)>\Pi_{p}(L \mid w)$. Then, $q^{*}$ should be equal to the minimum one between $D / \beta$ and $F^{-1}\left(1-c_{r} / \eta /\left(w-c_{e}\right)\right)$.

From Proposition 1, we can see that if $w$ is no higher than the sum of the unit production cost of electricity generated by wave energy converters and the transformed construction cost of unit maximum amount of electricity (i.e., $c_{e}+c_{r} / \eta$ ), then the port has no motivation for investing in the wave energy converters because purchasing traditional electricity from the plant is more beneficial than investing in wave energy converters. If $w>c_{r} / \eta+c_{e}$, then the port may benefit from operating her own wave energy converters within a limited range. Because the electricity generated from wave energy in a period is uncertain, the marginal cost saving from wave energy is decreasing with $q$. In addition, considering that $c_{e}$ and $c_{r} / \eta$ influence the marginal cost of wave energy, we can find that a higher $c_{e}$ or $c_{r} / \eta$ may make the port to invest less in the wave energy converters. On the other hand, however, $w$ presents the marginal cost saving of wave energy. Therefore, a higher $w$ could encourage the port to invest more in the wave energy converters, which implies a higher amount of electricity converted from the wave energy (see Equation (2)).

When $U$ and $q$ are greater than $D / \beta$, the wave energy might satisfy the port's demand of the electricity and the port does not need to purchase traditional electricity from the plant. If there is no salvage value of the electricity generated by the wave energy converters, $q^{*}$ is limited within the range of $[0, D / \beta]$ because the port only needs to generate at most $D / \beta$ units of electricity. However, in the real world, it is common that this type of surplus electricity can be sold to the market via the electricity plant's grid. Therefore, we discuss the case wherein the amount of electricity generated by the wave energy converters exceeds $D / \beta$. Suppose that the converters generate as much electricity as they can. In this case, we can obtain the amount of electricity generated by the wave energy converters, $A G$ as follows.

$$
A G= \begin{cases}x & x \leq q \\ q & q<x \leq U\end{cases}
$$


Next, we can obtain the amount of electricity purchased from the plant, $A P$, as follows.

$$
A P= \begin{cases}(D / \beta-x) & x \leq D / \beta \\ 0 & D / \beta<x \leq U\end{cases}
$$

The salvage amount, AS, can be obtained as follows.

$$
A S= \begin{cases}0 & x \leq D / \beta \\ x-D / \beta & D / \beta<x \leq q \\ q-D / \beta & q<x \leq U\end{cases}
$$

If $q \geq L$ and $L \leq D / \beta$, we can obtain the port's expected profit function as Equation (7) shows.

$$
\begin{aligned}
\Pi_{p}(q \mid w)=p D & -c_{e}\left(\int_{L}^{q} x f(x) d x+\int_{q}^{U} q f(x) d x\right)-\frac{c_{r}}{\eta} q-w \int_{L}^{D / \beta}\left(\frac{D}{\beta}-x\right) f(x) d x \\
& +s\left(\int_{D / \beta}^{q}\left(x-\frac{D}{\beta}\right) f(x) d x+\int_{q}^{U}\left(q-\frac{D}{\beta}\right) f(x) d x\right)
\end{aligned}
$$

Because the electricity plant is unlikely to purchase the electricity from the port at a price higher than $w$, we assume that $s \leq w$ and the port prefers using the electricity generated by her own wave energy converters (if any) to the traditional electricity purchased from the plant. As a consequence, we can obtain that the port's optimal $q$ is the same with Proposition 1 when $q$ is limited within the range of $[0, D / \beta]$. Next, we discuss the case wherein $q$ is no smaller than $D / \beta$.

Proposition 2. Suppose that the port invests in the wave energy converters and surplus electricity has a salvage value, s. We have

(i) if $s \leq c_{e}+c_{r} / \eta$ and $q \geq D / \beta$, then $q^{*}=D / \beta$.

(ii) if $s>c_{e}+c_{r} / \eta$ and $q \geq D / \beta$, and

$$
q^{*}=\max \left\{\frac{D}{\beta}, F^{-1}\left(1-\frac{c_{r}}{\eta\left(s-c_{e}\right)}\right)\right\}
$$

Proof. (i) From Equation (7), we can obtain that $d \Pi_{p}(q \mid w) / d q=-c_{r} / \eta+\left(s-c_{e}\right)(1-F(q))$. If $s-c_{e}$ $\leq c_{r} / \eta$, then $d \Pi_{p}(q \mid w) / d q$ is always smaller than 0 for any $q$ because $(1-F(q))$ is no greater than 1 . It means that $\Pi_{p}(q \mid w)$ is decreasing with $q$ and the optimal $q$ is equal to $D / \beta$ when $q$ is limited within the range of $[D / \beta, U]$.

(ii) Because $s>0$, we can obtain $\frac{d^{2} \Pi_{p}(q \mid w)}{d q^{2}}=-\left(s-c_{e}\right) f(q)<0$ and $\Pi_{p}(q \mid w)$ will achieve the maximum value with $q^{*}$ that satisfies $d \Pi_{p}\left(q^{*} \mid w\right) / d p=0$ when $q$ is greater than 0 . In this case, $q^{*}=F^{-1}\left(1-c_{r} / \eta /\left(s-c_{e}\right)\right)$ and $\Pi_{p}(q \mid w)$ is increasing with $q$ when $q$ is no greater than $F^{-1}\left(1-c_{r} / \eta /\left(s-c_{e}\right)\right)$ and $s>c_{e}+c_{r}$. As a consequence, we can find that $\Pi_{p}(q \mid w)$ is increasing with $q$ within the range of $\left[0, F^{-1}\left(1-c_{r} / \eta /\left(s-c_{e}\right)\right)\right]$. Moreover, $d \Pi_{p}(q \mid w) / d q<0$ when $q$ is greater than $F^{-1}\left(1-c_{r} / \eta /\left(s-c_{e}\right)\right)$. It means that $\Pi_{p}(q \mid w)$ is decreasing within the range of $\left[F^{-1}\left(1-c_{r} / \eta /\left(s-c_{e}\right)\right), U\right]$. Then, $q^{*}$ should be equal to the larger one between $D / \beta$ and $F^{-1}\left(1-c_{r} / \eta /\left(s-c_{e}\right)\right)$ when $q$ is limited within the range of $[D / \beta, U]$. It is also easy to show the conclusions in the above two proofs still hold when $L>D / \beta$.

According to Propositions 1 and 2, we can see that $q^{*}$ depends on the relationship among $F^{-1}\left(1-c_{r} / \eta /\left(w-c_{e}\right)\right), D / \beta$, and $F^{-1}\left(1-c_{r} / \eta /\left(s-c_{e}\right)\right)$. Note that $F^{-1}\left(1-c_{r} / \eta /\left(w-c_{e}\right)\right) \geq F^{-1}(1-$ $\left.c_{r} /\left(s-c_{e}\right)\right)$ because $w$ is no smaller than $s$. As a consequence, we have $q^{*}=F^{-1}\left(1-c_{r} / \eta /\left(w-c_{e}\right)\right)$ when 
$F^{-1}\left(1-c_{r} / \eta /\left(w-c_{e}\right)\right) \leq D / \beta$ and $q^{*}=F^{-1}\left(1-c_{r} / \eta /\left(s-c_{e}\right)\right)$ when $F^{-1}\left(1-c_{r} / \eta /\left(s-c_{e}\right)\right) \geq D / \beta$. In particular, $q^{*}=D / \beta$ when $F^{-1}\left(1-c_{r} / \eta /\left(w-c_{e}\right)\right)>D / \beta>F^{-1}\left(1-c_{r} / \eta /\left(s-c_{e}\right)\right)$.

Similar with the overstock cost in inventory management, the port needs to consider the potential loss of overinvestment in the wave energy converters. From Proposition 2, we can see that a higher $s$ implies a higher possibility that $q^{*}=F^{-1}\left(1-c_{r} / \eta /\left(s-c_{e}\right)\right)$. In particular, if $s$ is equal to $w$, then the profit of the port when $q>D / \beta$ is the same with Equation (3). In this case, the optimal $q$ of the port is equal to $F^{-1}\left(1-c_{r} / \eta /\left(w-c_{e}\right)\right)$ when $w>c_{r} / \eta+c_{e}$. It implies that the upper bound on $q^{*}$ is increasing with $s$. This finding means that when the salvage value of electricity is higher, the overinvestment loss is lower and the port is more incentivized to invest in the wave energy converters. Hence, the government can encourage the port to invest in wave energy by setting a relatively high lower bound on $s$. Table 2 summarized $q^{*}$ under difference cases when $w \geq s>c_{e}+c_{r} / \eta$.

Table 2. $q^{*}$ under difference cases when $w>s>c_{e}+c_{r} / \eta$.

\begin{tabular}{cc}
\hline Condition & $\boldsymbol{q}^{*}$ \\
\hline$F^{-1}\left(1-c_{r} / \eta /\left(w-c_{e}\right)\right)<D / \beta$ & $F^{-1}\left(1-c_{r} / \eta /\left(w-c_{e}\right)\right)$ \\
$F^{-1}\left(1-c_{r} / \eta /\left(s-c_{e}\right)\right)>D / \beta$ & $F^{-1}\left(1-c_{r} / \eta /\left(s-c_{e}\right)\right)$ \\
\hline$F^{-1}\left(1-c_{r} / \eta /\left(s-c_{e}\right)\right)<D / \beta<F^{-1}\left(1-c_{r} /\left(w-c_{e}\right)\right)$ & $D / \beta$ \\
\hline
\end{tabular}

\subsection{The Case Wherein the Electricity Plant Invests in the Wave Energy Converters}

Let $\Pi_{e}(q \mid w)$ be the profit function of the port. When the electricity plant invests in the wave energy converters and $L \leq q \leq U, \Pi_{e}(q \mid w)$ can be written as follows.

$$
\begin{aligned}
& \Pi_{\mathcal{e}}(q \mid w) \\
& =w \frac{D}{\beta}-c_{e}\left(\int_{L}^{q} x f(x) d x+\int_{q}^{U} q f(x) d x\right)-\frac{c_{r}}{\eta} q-c_{t}\left(\frac{D}{\beta}-\int_{L}^{q} x f(x) d x-\int_{q}^{U} q f(x) d x\right)
\end{aligned}
$$

For the deal between the port and the electricity plant, the total revenue of the plant is $w D / \beta$. He obtains this revenue by supplying wave-energy electricity and traditional electricity if the former cannot meet the port's demand. The second and third terms in Equation (9) present the production and construction costs related to wave energy, respectively. When the electricity generated by the wave energy converters is smaller than $D / \beta$, (i.e., $\left.\frac{D}{\beta} \geq \int_{L}^{q} x f(x) d x+\int_{q}^{U} q f(x) d x\right)$ the port needs to use the traditional electricity to satisfy the port's demand and the corresponding cost is $c_{t}\left(\frac{D}{\beta}-\int_{L}^{q} x f(x) d x-\int_{q}^{U} q f(x) d x\right)$. When the electricity generated by the wave energy converters is greater than $D / \beta$ (i.e., $\left.\frac{D}{\beta}<\int_{L}^{q} x f(x) d x+\int_{q}^{U} q f(x) d x\right)$, the exceeding amount of this electricity will be sold to other customers to replace the traditional electricity. In this case, $\Pi_{e}(q \mid w)$ can be increased by $c_{t}\left(\int_{L}^{q} x f(x) d x-\int_{q}^{U} q f(x) d x-\frac{D}{\beta}\right)$. On the basis of the above discussion, we can obtain the fourth term in Equation (9). When $q \leq L, \Pi_{e}(q \mid w)=\left(w-c_{t}\right) D / \beta+\left(c_{t}-c_{e}\right) q-c_{r} q / \eta$. Let $q^{e}$ be the plant's optimal $q$ to maximize his own profit.

Proposition 3. Suppose that the electricity plant invests in the wave energy converters.

(i) if $c_{t} \leq c_{e}+c_{r} / \eta$, then $q^{e}=0$.

(ii) otherwise, $q^{e}$ satisfies

$$
q^{e}=F^{-1}\left(1-\frac{c_{r}}{\eta\left(c_{t}-c_{e}\right)}\right)
$$


Proof.

(i) When, $L \leq q \leq U$, Objective Function (9) can be written as

$$
\begin{aligned}
& \Pi_{e}(q \mid w) \\
& =\left(w-c_{e}\right)\left(\int_{L}^{q} x f(x) d x+\int_{q}^{U} q f(x) d x\right)-c_{r} q+\left(w-c_{t}\right)\left(\frac{D}{\beta}-\int_{L}^{q} x f(x) d x-\int_{q}^{U} q f(x) d x\right) \\
& =\left(c_{t}-c_{e}\right)\left(\int_{L}^{q} x f(x) d x+\int_{q}^{U} q f(x) d x\right)-c_{r} q+w \frac{D}{\beta}
\end{aligned}
$$

With the methodology used in the proof of Proposition 1, we can obtain that $d \Pi_{\mathcal{e}}(q \mid w) / d q=\left(c_{t}-\right.$ $\left.c_{e}\right)(1-F(q))-c_{r} / \eta$. Considering that $0 \leq F(q) \leq 1$ for any a $q \in[L, U], d \Pi_{e}(q \mid w) / d p$ is always smaller than zero if $c_{t}-c_{e} \leq c_{r} / \eta$. In this case, the profit of the plant is always decreasing with $q$ and then $q^{e}=L$. When $q \leq L, \Pi_{e}(q \mid w)=\left(w-c_{t}\right) D / \beta+\left(c_{t}-c_{e}\right) q-c_{r} q / \eta$ and we can obtain $q^{e}=0$ and $\Pi_{e}(0 \mid w)$ $>\Pi_{e}(L \mid w)$. Hence, we can obtain that $q^{e}=0$ if $c_{t} \leq c_{e}+c_{r} / \eta$.

(ii) With the same method of the proof of Proposition 1, we can find that $q^{e}$ should be equal to $F^{-1}(1$ $\left.-c_{r} / \eta /\left(c_{t}-c_{e}\right)\right)$.

Proposition 3 tells that the plant's optimal $q$ is influenced by the unit cost of traditional electricity. If this unit cost is smaller than $c_{e}+c_{r} / \eta$, then the plant will not invest in the wave energy converters, i.e., $q^{e}=0$. If $c_{t} / \eta \geq c_{r}+c_{e}$, then the plant may find it profitable to operating his own wave energy converters within a certain range. Moreover, a lower unit cost related to the wave energy, (i.e., $c_{e}$ and $c_{r} / \eta$ ) may pull the plant to invest more in it. However, a lower unit cost of traditional electricity could weaken the plant's motivation for the investment in wave energy converters.

By comparing $q^{e}$ and $q^{*}$ obtained from Propositions 1 and 3, we can see that in many cases the port is more incentivized than the plant to use the wave energy. For example, $q^{*}>q^{e}$ when $F^{-1}\left(1-c_{r} / \eta /\left(w-c_{e}\right)\right)<D / \beta$. The reason could be as follows. When the port invests in the wave energy and $q \leq D / \beta$, her marginal benefit of $q$ is $\left(w-c_{e}\right) F(q)-c_{r} / \eta . F(q)$ represents the possibility of obtaining one unit electricity at $q$. For such a unit, the port needs to invest $c_{r} / \eta$ for the construction of the wave energy converters. The expected unit production cost for the electricity is $c_{e} F(q)$. In addition, every unit's electricity generated by the wave energy converters can save the port's cost by $w$, which is the price that the port pays to the plant for unit electricity. Meanwhile, when the plant invests in the wave energy, his marginal benefit of $q$ is $\left(c_{t}-c_{e}\right) F(q)-c_{r} / \eta$. The difference between the port and the plant is that the latter's marginal benefit results in the difference between the unit production cost of the traditional electricity and the overall unit cost of the wave energy. Because $w$ is higher than $c_{t}$ in the real world, unit electricity from the wave energy can save more cost for the port than the plant. As a consequence, we can see that the port might invest more in the wave energy than the plant when the production amount is uncertain. Figure 2 illustrates the marginal benefits and costs of wave energy converters of the port and the electricity plant.

When $q$ is required to be no smaller than $D / \beta$, the expected amount of traditional electricity purchased from the plant is fixed as $\int_{L}^{\frac{D}{\beta}}\left(\frac{D}{\beta}-x\right) f(x) d x$. The marginal benefit of $q$ is $\left(s-c_{\mathcal{e}}\right) F(q)-c_{r} / \eta$. If $s$ is no greater than $c_{e}$, then the port cannot make a profit by selling the surplus electricity to the grid and he will select the minimum investment value, i.e., $D / \beta$. Supposing that $w>c_{t}>c_{r} / \eta+c_{e}$, it is easy to show that $q^{*}>q^{e}$ when $s>c_{t}$. Table 3 summarized the comparison between $q^{*}$ and $q^{e}$ under different cases, from which we can see the motivation of the port and plant for investing in wave energy converters. 


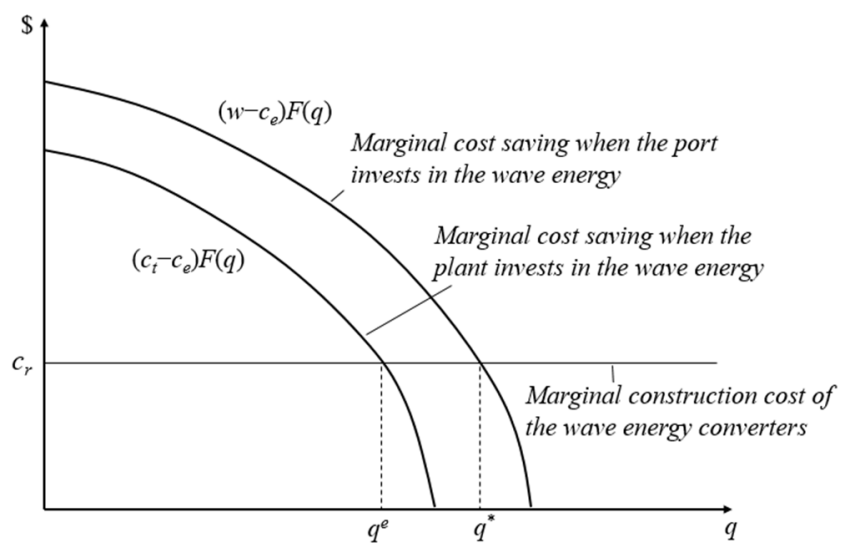

Figure 2. Marginal benefits and costs of wave energy converters.

Table 3. Comparison between $q^{*}$ and $q^{e}$ under different cases.

\begin{tabular}{cc}
\hline Condition & Relationship between $\boldsymbol{q}^{*}$ and $\boldsymbol{q}^{e}$ \\
\hline$F^{-1}\left(1-c_{r} / \eta /\left(w-c_{e}\right)\right)<D / \beta$ & $q^{*}>q^{e}$ \\
$s>c_{t}$ & $q^{*}>q^{e}$ \\
$F^{-1}\left(1-c_{r} / \eta /\left(s-c_{e}\right)\right)>D / \beta$ and $s<c_{t}$ & $q^{*}<q^{e}$ \\
$F^{-1}\left(1-c_{r} / \eta /\left(s-c_{e}\right)\right)<D / \beta<F^{-1}\left(1-c_{r} / \eta /\left(w-c_{e}\right)\right)$ and $s<c_{t}$ & $q^{*}>q^{e}$ \\
and $F^{-1}\left(1-c_{r} / \eta /\left(c_{t}-c_{e}\right)\right)<D / \beta$ & \\
$F^{-1}\left(1-c_{r} / \eta /\left(s-c_{e}\right)\right)<D / \beta<F^{-1}\left(1-c_{r} / \eta /\left(w-c_{e}\right)\right)$ & $q^{*}<q^{e}$ \\
and $s<c_{t}$ and $F^{-1}\left(1-c_{r} / \eta /\left(c_{t}-c_{e}\right)\right)>D / \beta$ & \\
\hline
\end{tabular}

\subsection{Extension: Distribution-Free Model}

For the seek of simplicity, we assume that $s$ is equal to $w$ in this subsection. We only discuss the case wherein the port invests in the wave energy converters. The discussion of the cases wherein the electricity plant invests in the converters will be similar. According to Propositions 1 and 2, we can obtain that $q^{*}=F^{-1}\left(1-c_{r} /\left(w-c_{e}\right)\right)$ when $s=w$. The profit function of the port can be written as

$$
\Pi_{p}(q \mid w)=p D+\left(w-c_{e}\right) \operatorname{Emin}(q, X)-c_{r} q / \eta-w D / \beta
$$

Because $\min (q, X)=X-(X-q)^{+}$, we can obtain that $E \min (q, X)=\mu-E(X-q)^{+}$

$$
\Pi_{p}(q \mid w)=p D+\left(w-c_{e}\right) \mu+\left(w-c_{e}\right) E(q-X)^{+}-c_{r} q / \eta-w D / \beta
$$

Based on the findings of Scarf [28] and Gallego and Moon [29], we can obtain Proposition 4 as follows.

Proposition 4. Given $\mu$ and $\sigma$, there exists a lower bound of $\Pi_{p}(q \mid w)$, and the $q$ that maximizes this lower bound, i.e., $q^{d}$, satisfies

(i) when $w-c_{e}-2 c_{r} \geq 0$,

$$
q^{d}=\mu+\frac{\left(w-c_{e}-2 \frac{c_{r}}{\eta}\right) \sigma}{2 \sqrt{\frac{c_{r}}{\eta}\left(w-c_{e}-\frac{c_{r}}{\eta}\right)}}
$$

(ii) when $w-c_{e}-2 c_{r}<0$,

$$
q^{d}=\mu-\frac{\left(w-c_{e}-2 \frac{c_{r}}{\eta}\right) \sigma}{2 \sqrt{\frac{c_{r}}{\eta}\left(w-c_{e}-\frac{c_{r}}{\eta}\right)}}
$$


Proof. We combine the proofs of (i) and (ii) as follows. According to the findings of Scarf [28] and Gallego and Moon [29], we have

$$
E(X-q)^{+} \leq \frac{\sqrt{\sigma^{2}+(q-\mu)^{2}}-(q-\mu)}{2}
$$

It means that without specifying a distribution of $X$, we always have

$$
\Pi_{p}(q) \geq p D+\left(w-c_{e}\right) \mu-\left(w-c_{e}\right) \frac{\sqrt{\sigma^{2}+(q-\mu)^{2}}-(q-\mu)}{2}-\frac{c_{r}}{\eta} q-w \frac{D}{\beta}
$$

Let $G(q)=p D+\left(w-c_{e}\right) \mu-\left(w-c_{e}\right) \frac{\sqrt{\sigma^{2}+(q-\mu)^{2}}-(q-\mu)}{2}-\frac{c_{r}}{\eta} q-w \frac{D}{\beta}$.

In order to maximize $G(q)$, we have

$$
\frac{d G(q)}{d q}=-\frac{\left(w-c_{e}\right)}{2}\left(\frac{q-\mu}{\sqrt{\sigma^{2}+(q-\mu)^{2}}}-1\right)-c_{r}
$$

and

$$
\frac{d^{2} G(q)}{d q^{2}}=\frac{-\sigma^{2}}{\sqrt{\sigma^{2}+(q-\mu)^{2}}\left(\sigma^{2}+(q-\mu)^{2}\right)}
$$

Because $d^{2} G(q) / d q^{2}<0$, the $q$ that satisfies $d G(q) / d q=0$ can maximize $G(q)$.

By setting $d G\left(q^{d}\right) / d q=0$, we can obtain

$$
\left(w-c_{e}\right) \frac{\left(q^{d}-\mu\right)}{\sqrt{\sigma^{2}+\left(q^{d}-\mu\right)^{2}}}=w-c_{e}-2 \frac{c_{r}}{\eta}
$$

From Equation (20), we can infer that $q^{d}-\mu \geq 0$ when $w-c_{e}-2 c_{r} / \eta \geq 0$ and $q^{d}-\mu<0$ when $w$ $-c_{e}-2 c_{r} / \eta<0$. In addition, we have

$$
4 c_{r}\left(w-c_{e}-c_{r} / \eta\right)\left(q^{d}-\mu\right)^{2}=\left(w-c_{e}-2 c_{r} / \eta\right)^{2} \sigma^{2}
$$

Therefore, $q^{d}$ should satisfy Equation (14) when $w-c_{e}-2 c_{r} / \eta \geq 0$, and should satisfy Equation (15) when $w-c_{e}-2 c_{r} / \eta<0$.

Proposition 4 shows the $q^{d}$ that maximizes the lower bound on $\Pi_{p}(q \mid w)$ when only $\mu$ and $\sigma$ of $X$ are known. We can see the motivation of distribution-free model as follows. In the practice, it can be used when collecting the full information of $X$ is time consuming or costly. In the real world, assuming a distribution and using the corresponding $q^{*}$ or $q^{e}$ might result in great loss. In this case, $q^{d}$ would be an appropriate scenario that can maximize the lower bound on the profit. Moreover, in some cases, even though it is possible to point out the distribution of $X$, this work could be costly. Then, $q^{d}$ can be used to evaluate the benefit of this work. Suppose that the port would like to verify whether $X$ follows a uniform distribution. We can obtain $q^{*}$ by assuming that $X$ follows a uniform distribution and the corresponding profit. We can also obtain the profit under $q^{d}$ and that same uniform distribution. Certainly, the profit under $q^{*}$ is higher than the one under $q^{d}$. However, if this profit gap is smaller than the research fee required to verify the distribution, then directly implementing the distribution-free model (i.e., $q^{d}$ ) is more beneficial than verifying the distribution and using $q^{*}$. This profit gap is also known as the Expected Value of Additional Information [29]. Hence, the distribution-free model can also be used to evaluate the performance of this verification. 


\section{Numerical Example}

We conduct a numerical example to illustrate the optimal decisions of the port and electricity plant, and the impact of parameters. Suppose that a port terminal's annual cargo throughput is 100 million tons and $\beta=1000$ ton per MWh. Then, the electricity demand, i.e., $D / \beta$, is $100 \mathrm{GWh}$. Assume that $s$ is $500 \mathrm{CNY}$ per MWh, $c_{r} / \eta$ is $400 \mathrm{CNY}$ per MWh, $c_{e}$ is $50 \mathrm{CNY}$ per MWh, and $c_{t}$ is $500 \mathrm{CNY}$ per MWh. Suppose $X$ in one year follows uniform distribution. Let $L=80,000 \mathrm{MWh}$ and $U=140,000 \mathrm{MWh}$. In this case, $F^{-1}\left(1-c_{r} / \eta /\left(s-c_{e}\right)\right)$ is smaller than $D / \beta$. Let $E C T(q)$ be the expected cargo throughput in tons supported by the electricity from wave energy. We have $\operatorname{ECT}(q)=($ Expected $A G(q)) \times \beta$. From Table 4 , we can see that $q^{*}$ is increasing with $w$ when $w$ is within a certain range. For a small $w, F^{-1}\left(1-c_{r} / \eta /\left(w-c_{e}\right)\right)$ is smaller than $D / \beta$ and $q^{*}=F^{-1}\left(1-c_{r} / \eta /\left(w-c_{e}\right)\right.$. When $w$ reaches a threshold, $F^{-1}\left(1-c_{r} / \eta /\left(w-c_{e}\right)\right.$ is higher than $D / \beta$ that will be the value of $q^{*}$ (see Table 3$)$. According to Table 3 and $c_{t}$, we can obtain that $q^{*}$ is no smaller than $q^{e}$, and the port is more incentivized to invest in wave energy converters than the electricity plant when $w$ is higher than $600 \mathrm{CNY}$ per MWh. According to $\beta=1000$ ton per MWh, we have the amounts of cargo throughput (in ton) supported by the wave-energy electricity, as $\operatorname{ECT}\left(q^{*}\right)$ and $\operatorname{ECT}\left(q^{e}\right)$ show.

Table 4. Impact of salvage value of the price of traditional electricity.

\begin{tabular}{ccccccc}
\hline $\boldsymbol{w}$ & $\boldsymbol{q}^{*}$ & $\boldsymbol{q}^{\boldsymbol{e}}$ & Expected $A G\left(q^{*}\right)$ & Expected $A G\left(q^{\boldsymbol{e}}\right)$ & $\boldsymbol{E C T}\left(q^{*}\right)$ & $\boldsymbol{E C T}\left(q^{\boldsymbol{e}}\right)$ \\
\hline 600 & 96,364 & 86,667 & 94,132 & 986,929 & $94,132,000$ & $86,929,000$ \\
620 & 97,895 & 86,667 & 95,226 & 986,929 & $95,226,000$ & $86,929,000$ \\
640 & 99,322 & 86,667 & 96,211 & 986,929 & $96,211,000$ & $86,929,000$ \\
660 & 100,000 & 86,667 & 96,667 & 986,929 & $96,667,000$ & $86,929,000$ \\
680 & 100,000 & 86,667 & 96,667 & 986,929 & $96,667,000$ & $86,929,000$ \\
\hline
\end{tabular}

When $w=800$ CNY per MWh, $F^{-1}\left(1-c_{r} / \eta /\left(w-c_{e}\right)\right)$ is still higher than $D / \beta$. In this case, $F^{-1}\left(1-c_{r} / \eta /\left(s-c_{e}\right)\right)$ is smaller than $D / \beta$ and $q^{*}=D / \beta$ when $s$ is small. Hence, $q^{*}$ is equal to 100 when $s$ is no higher than $650 \mathrm{CNY}$ per MWh. When $s$ reaches a threshold, $F^{-1}\left(1-c_{r} / \eta /\left(s-c_{e}\right)\right.$ is higher than $D / \beta$ and $q^{*}=F^{-1}\left(1-c_{r} / \eta /\left(s-c_{e}\right)\right)$, as Table 3 illustrates. From Table 5 , we can see that $q^{*}$ is increasing with $s$ when $s$ is higher than 650 CNY per MWh. Therefore, we can conjecture that the government can encourage the port to invest more in wave energy converters by setting a higher $s$. On the other hand, however, this policy will not influence the electricity plant's motivation for wave energy. Table 5 also illustrates $\operatorname{ECT}\left(q^{*}\right)$ and $\operatorname{ECT}\left(q^{e}\right)$ when $s$ is increasing. When $s$ is no lower than $750 \mathrm{CNY}$ per MWh and the port invests in wave energy converters, expected $A G\left(q^{*}\right)$ is higher than $D / \beta$ and all of the workload of the port can be covered by the wave-energy electricity, i.e., $E C T\left(q^{*}\right)=D / \beta$. The excess wave-energy electricity under $q^{*}$ when $s$ is equal to 750 and $800 \mathrm{CNY}$ per MWh is 206 and $1467 \mathrm{MWh}$. In these cases, the port can obtain revenue of 154.5 and 1173.6 thousand CNY.

Table 5. Impact of salvage value of wave-energy electricity when $w=800$ CNY per MWh.

\begin{tabular}{ccccccc}
\hline $\boldsymbol{s}$ & $\boldsymbol{q}^{*}$ & $\boldsymbol{q}^{\boldsymbol{e}}$ & Expected AG( $\left.q^{*}\right)$ & Expected $A G\left(q^{e}\right)$ & $\boldsymbol{E C T}\left(q^{*}\right)$ & $\boldsymbol{E C T}\left(q^{e}\right)$ \\
\hline 600 & 100,000 & 92,941 & 96,667 & 91,546 & $96,667,000$ & $91,546,000$ \\
650 & 100,000 & 92,941 & 96,667 & 91,546 & $96,667,000$ & $91,546,000$ \\
700 & 103,077 & 92,941 & 98,639 & 91,546 & $98,639,000$ & $91,546,000$ \\
750 & 105,717 & 92,941 & 100,206 & 91,546 & $100,000,000$ & $91,546,000$ \\
800 & 108,000 & 92,941 & 101,467 & 91,546 & $100,000,000$ & $91,546,000$ \\
\hline
\end{tabular}

Because $c_{e}$ and $c_{r} / \eta$ have similar impacts on the optimal decisions, we only show the results when $c_{e}$ varies. As Table 6 shows, when $c_{e}$ is between 10 and $50 \mathrm{CNY}$ per MWh, $q^{*}$ and $q^{e}$ are decreasing with $c_{e}$. 
Table 6. Impact of unit production cost of wave-energy electricity.

\begin{tabular}{ccccccc}
\hline$c_{\boldsymbol{e}}$ & $\boldsymbol{q}^{*}$ & $\boldsymbol{q}^{\boldsymbol{e}}$ & Expected $A G\left(q^{*}\right)$ & Expected $A G\left(q^{\boldsymbol{e}}\right)$ & $\boldsymbol{E C T}\left(q^{*}\right)$ & $\boldsymbol{E C T}\left(q^{\boldsymbol{e}}\right)$ \\
\hline 10 & 99,322 & 91,020 & 96,211 & 90,008 & $96,211,000$ & $90,008,000$ \\
20 & 98,621 & 90,000 & 95,731 & 89,167 & $95,731,000$ & $89,167,000$ \\
30 & 97,895 & 88,936 & 95,226 & 88,271 & $95,226,000$ & $88,271,000$ \\
40 & 97,143 & 87,826 & 94,694 & 87,316 & $94,694,000$ & $87,316,000$ \\
50 & 96,364 & 86,667 & 94,133 & 86,296 & $94,133,000$ & $86,296,000$ \\
\hline
\end{tabular}

Table 7 shows the impact of $c_{t}$ on $q^{*}$ and $q^{e}$. We can see that $c_{t}$ has no influence on the port's decision, but has a significant effect on the electricity plant's motivation. When $c_{t}$ is lower than $c_{r}+c_{e}$, the plant has no motivation for investing in wave energy. When $c_{t}$ is high, the cost advantage of the traditional electricity will be lower and the plant would like to invest more in wave energy converters. There also exist cases wherein the plant has the same motivation for the investment with the port. It implies that governments can increase $q^{e}$ by charging the plant a penalty cost for unit traditional electricity to increase $c_{t}$.

Table 7. Impact of unit production cost of traditional electricity.

\begin{tabular}{ccccccc}
\hline$c_{t}$ & $q^{*}$ & $q^{e}$ & Expected $A G\left(q^{*}\right)$ & Expected $A G\left(q^{e}\right)$ & ECT $\left(q^{*}\right)$ & ECT $\left(q^{e}\right)$ \\
\hline 400 & 96,364 & 0 & 95,695 & 0 & $95,695,000$ & 0 \\
450 & 96,364 & 80,000 & 95,695 & 80,000 & $95,695,000$ & $80,000,000$ \\
500 & 96,364 & 86,667 & 95,695 & 86,556 & $95,695,000$ & $86,556,000$ \\
550 & 96,364 & 92,000 & 95,695 & 91,640 & $95,695,000$ & $91,640,000$ \\
600 & 96,364 & 96,364 & 95,695 & 95,695 & $95,695,000$ & $95,695,000$ \\
\hline
\end{tabular}

In order to see the impact of wave supply condition and how distribution-free model works, we set $w=600 \mathrm{CNY}$ per MWh, $s=500 \mathrm{CNY}$ per MWh, and conducted experiments on different pairs of $\{a, b\}$. Because $F^{-1}\left(1-c_{r} / \eta /\left(s-c_{e}\right)\right.$ is higher than $D / \beta, q^{*}$ is equal to $F^{-1}\left(1-c_{r} / \eta /\left(s-c_{e}\right)\right.$ and it is decreasing when the standard deviation of $X$ is decreasing, as Table 8 shows. In addition, $q^{d}$ is more closed to $q^{*}$ with a smaller standard deviation of $X$, and the profit gap between $\Pi_{p}\left(q^{*}\right)$ and $\Pi_{p}\left(q^{d}\right)$ is smaller. According to the profit gaps, we can tell whether it is beneficial to spend money to verify the exact probability distribution.

Table 8. Impact of wave supply condition (the same mean value and different standard deviations).

\begin{tabular}{cccccccc}
\hline $\boldsymbol{L}$ & $\boldsymbol{U}$ & $\boldsymbol{q}^{*}$ & $\boldsymbol{q}^{\boldsymbol{e}}$ & Expected $\boldsymbol{A G}\left(\boldsymbol{q}^{*}\right)$ & Expected $\boldsymbol{A} G\left(\boldsymbol{q}^{\boldsymbol{e}}\right)$ & $\boldsymbol{q}^{\boldsymbol{d}}$ & Profit Gap \\
\hline 0 & 200,000 & 54,545 & 22,222 & 47,107 & 20,987 & 70,537 & 351,638 \\
20,000 & 180,000 & 63,636 & 37,777 & 57,686 & 36,789 & 76,430 & 281,310 \\
40,000 & 160,000 & 72,727 & 53,333 & 68,264 & 52,592 & 82,322 & 210,983 \\
60,000 & 140,000 & 81,818 & 68,889 & 78,843 & 68,395 & 88,215 & 140,655 \\
80,000 & 120,000 & 90,909 & 84,444 & 89,421 & 84,197 & 94,107 & 70,328 \\
\hline
\end{tabular}

\section{Managerial Insights and Policy Suggestions on Encouraging Green Ports}

The optimization of construction of wave energy converters and production of wave-energy electricity can be modeled as a newsvendor problem when the wave supply is uncertain. If there is no salvage value of wave-energy electricity generated by the port, then the port has no incentive to invest in wave energy converters to hold a capacity beyond her electricity demand. If $F^{-1}\left(1-c_{r} / \eta /\left(w-c_{e}\right)\right)$ is smaller than the demand, then the port's willingness of investing in the converters is higher when $w$ is increased. Hence, governments can encourage ports to implement wave energy by setting a higher lower bound on the price of the traditional electricity charged by the plant. In addition, the port's willingness is negatively associated with the construction cost of wave energy converters. It implies that governments can offer some subsidy to reduce the construction cost. However, it should be 
noted that the above suggested polices are not always efficient. Without a salvage value of surplus wave-energy electricity, the port will not benefit from investing more in wave energy when the wave-energy electricity satisfies the demand.

In order to encourage the port to invest more in wave energy, governments can help the port to sell the surplus wave-energy electricity to the grid. If the salvage value is low, then the port may find a high $q$ not beneficial. Therefore, governments needs to set a high lower bound on $s$ so that the port can get more by selling surplus electricity. For example, the government can offer incentive money to the port for unit wave-energy electricity sent to the grid. Meanwhile, it is not certain that the port's willingness of investing in wave energy is always positively impacted by s. There exists a lower bound on $s$ to encourage the port to generate more electricity from wave energy than her demand.

On the electricity plant side, because the plant will lose interest in wave-energy electricity when $c_{t} \leq c_{e}+c_{r} / \eta$, governments need to design policies by considering the costs of both wave-energy electricity and traditional electricity. For example, governments can charge the plant a penalty cost for unit traditional electricity to increase $c_{t}$. Another potential policy is to give subsidy on unit wave-energy electricity to reduce $c_{e}$. Governments can also invest in research and development of new wave energy converter technologies to reduce $c_{r}$.

Among existing types of wave energy converters, only some types are appropriate to be entirely embedded in the breakwaters of ports, such as Oscillating Water Column and Over Topping Device [30-32]. In this case, the total construction cost of wave energy converters and breakwaters could be lower, and the overall benefit will be increased. If the electricity plant invest in wave energy converters, he may try to find approaches of sharing this cost with the port because the construction waive a part of construction cost of breakwater of the port. Governments may find space to guide the port and plant to share the construction cost of wave energy converters embedded in the breakwater to encourage the investment in wave energy that can also decrease the total construction cost including breakwaters.

\section{Conclusions and Future Work}

According to the characteristics of wave energy, we developed mathematical models to analyze the optimal decisions of the port and the electricity plant. When the cost of wave-energy electricity is higher than the expenditure of using traditional electricity (i.e., $w \leq c_{r} / \eta+c_{e}$ ), the port will have no interest in implementing wave energy because purchasing traditional electricity from the plant can be more beneficial. When $w>c_{r}+c_{e}$, the port may invest in wave energy converters. In particular, there is an upper bound on $q^{*}$, (i.e., $D / \beta$ ) if there is no salvage value of surplus electricity. In this case, $q^{*}$ is increasing with $w$ if $F^{-1}\left(1-c_{r} / \eta /\left(w-c_{e}\right)\right)<D / \beta$. When the port can sell surplus electricity to the grid with a salvage value, $q^{*}$ might be higher than the former case, and it is influenced by the value of $s$.

When the plant invests in wave-energy electricity, it can sell surplus wave-energy electricity to the grid at a price of $w$ that is usually higher than $s$. However, it does not mean that the plant is more incentivized to invest in wave energy converters than the port. Because the port's electricity demand is fixed, the amount of wave-energy electricity influences the cost of the plant rather than the revenue. Hence, it is the costs of wave-energy electricity and traditional electricity affects the willingness of the port for wave energy. We show that a higher $c_{t}$ makes the plant invest more in wave energy converters. By comparing the port and plant, we can see that there exist cases wherein each side has higher motivation for wave energy than the other. For example, if $F^{-1}\left(1-c_{r} / \eta /\left(s-c_{e}\right)\right)<D / \beta<F^{-1}\left(1-c_{r} / \eta /\left(w-c_{e}\right)\right), q^{*}=D / \beta$. In this case, $q^{e}$ will be higher than $q^{*}$ if $F^{-1}\left(1-c_{r} / \eta /\left(c_{t}-c_{e}\right)\right)>D / \beta$.

We also extend the port's model to distribution-free model, in which $\mu$ and $\sigma$ are known. Without specifying a distribution of wave energy supply in one period, we showed that there exists a lower bound of $\Pi_{p}(q \mid w)$, and obtained $q^{d}$ that maximizes this lower bound. By using this $q^{d}$, the port can guarantee a lower bound on her profit without knowing the distribution of wave energy supply. 
The port can also evaluate the benefit of investigating the wave energy supply with the extended model and findings. If it is time consuming or costly to get the distribution information, then the extended model can be used to make decisions to save time or obtain a solution which can maximize the lower bound of the expected profit.

This study can be extended in several directions. First, there exist areas wherein several ports are located, such as Zhejiang province, China [33]. It would be worthwhile to analyze the optimal capacities and layout of wave energy converters among these ports to design an efficient grid of wave-energy electricity. Second, considering that the wave energy supply condition is usually complex and dynamic, simulation models to determine the optimal decisions on the investment under specific wave supply conditions could also be a fruitful direction from the views of both academic and practical. Third, there are a large number of researchers who are developing technologies of wave energy converters. Governments, ports, and electricity plants would benefit from the advanced technologies. Because the research fee would be high and the outcome is uncertain, how to share the research fee and outcome will be essential to encourage those agents to invest in the research and technology. Therefore, it would be interesting to develop a contract to coordinate different agents' decisions on wave energy utilization. Fourth, it will also be worthwhile extending the model with the environmental cost-benefit analysis [34]. Comprehensive subsidy and pricing schemes of government can be analyzed to improve the environmental benefit of wave energy converters.

Author Contributions: Conceptualization, L.L.; Formal analysis, J.Z. and G.Y.; Investigation, L.L.; Methodology, J.Z. and X.F.; Software, J.Z.; Writing—original draft, X.F.

Funding: This research was supported by the Interdisciplinary Research Fund of Zhejiang University [2017XZA113].

Conflicts of Interest: The authors declare no conflict of interest.

\section{Nomenclature}

Parameters:

D Port service demand in a period

$p \quad$ Port service price in a period

$X \quad$ The maximum amount of electricity that can be generated by the wave in a period,

$X \quad$ a random variable

$F(X) \quad$ Cumulative probability function of $X$

$F^{-1}(\bullet) \quad$ Inverse function of $F(X)$

$f(x) \quad$ Probability density function of $X$

$\mu \quad$ Mean value of $X$

$\sigma \quad$ Standard deviation of $X$

$U \quad$ Upper bound on the amount of electricity generated from the wave energy

$L \quad$ Lower bound on the amount of electricity generated from the wave energy

$\beta \quad$ Coefficient of the conversion between port service demand and required

$\beta \quad$ amount of electricity

$\eta \quad$ Coefficient of the conversion between capacity of wave energy converters and

$\eta \quad$ maximum amount of electricity in one period

$c_{r} \quad$ Construction cost of unit wave energy converter

$c_{e} \quad$ Production cost of unit amount of electricity generated by wave energy converters

Production cost of unit amount of traditional electricity, including a penalty fee

$c_{t} \quad$ charged by the government for environmental consideration

$w \quad$ Price of unit amount of electricity charged by the electricity plant

$s \quad$ Salvage value of unit amount of electricity generated by wave energy converters

Decision variable

Q The capacity of wave energy converters

q The maximum amount of electricity that can be generated by wave energy

$q$ converters in one period when the wave supply is infinite 


\section{References}

1. Li, K.X.; Park, T.J.; Lee, P.T.W.; McLaughlin, H.; Shi, W.M. Container transport network for sustainable development in South Korea. Sustainability 2018, 10, 3575. [CrossRef]

2. Kotrikla, A.M.; Lilas, T.; Nikitakos, N. Abatement of air pollution at an aegean island port utilizing shore side electricity and renewable energy. Mar. Policy 2017, 75, 238-248. [CrossRef]

3. Zhang, S.Z.; Ruan, X.; Xia, Y.Z.; Feng, X.H. Foldable container in empty container repositioning in intermodal transportation network of Belt and Road Initiative: Strengths and limitations. Marit. Policy Manag. 2018, 45, 351-369. [CrossRef]

4. Zhang, R.Y.; Zhao, H.S.; Moon, I.K. Range-based truck-state transition modeling method for foldable container drayage services. Transp. Res. Part E 2018, 118, 225-239. [CrossRef]

5. Gunn, K.; Stock-Williams, C. Quantifying the global wave power resource. Renew. Energy 2012, 44, $296-304$. [CrossRef]

6. Aoun, N.S.; Harajli, H.A.; Queffeulou, P. Preliminary appraisal of wave power prospects in Lebanon. Renew. Energy 2013, 53, 165-173. [CrossRef]

7. Drew, B.; Plummer, A.R.; Sahinkaya, M.N. A review of wave energy converter technology. J. Power Energy Proc. Inst. Mech. Eng. Part A 2009, 223, 887-902. [CrossRef]

8. Acciaro, M.; Ghiara, H.; Cusano, M.I. Energy management in seaports: A new role for port authorities. Energy Policy 2014, 71, 4-12. [CrossRef]

9. Chen, Z.; Pak, M. A Delphi analysis on green performance evaluation indices for ports in China. Marit. Policy Manag. 2017, 44, 537-550. [CrossRef]

10. Schipper, C.A.; Vreugdenhil, H.; de Jong, M.P.C. A sustainability assessment of ports and port-city plans: Comparing ambitions with achievements. Transp. Res. Part D 2017, 57, 84-111. [CrossRef]

11. Wan, C.P.; Zhang, D.; Yan, X.P.; Yang, Z.L. A novel model for the quantitative evaluation of green port development-A case study of major ports in China. Transp. Res. Part D 2018, 61, 431-443. [CrossRef]

12. Chen, C.; Lam, J.S.L. Sustainability and interactivity between cities and ports: A two-stage data envelopment analysis (DEA) approach. Marit. Policy Manag. 2018, 45, 944-961. [CrossRef]

13. Vaio, A.D.; Varriale, L.; Alvino, F. Key performance indicators for developing environmentally sustainable and energy efficient ports: Evidence from Italy. Energy Policy 2018, 122, 229-240. [CrossRef]

14. Shi, W.M.; Xiao, Y.; Chen, Z.; McLaughlin, H.; Li, K.X. Evolution of green shipping research: Themes and methods. Marit. Policy Manag. 2018, 45, 863-876. [CrossRef]

15. Iuppa, C.; Contestabile, P.; Cavallaro, L.; Foti, E.; Vicinanza, D. Hydraulic performance of an innovative breakwater for overtopping wave energy conversion. Sustainability 2016, 8, 1226. [CrossRef]

16. Naty, S.; Viviano, A.; Foti, E. Wave energy exploitation system integrated in the coastal structure of a Mediterranean port. Sustainability 2016, 8, 1342. [CrossRef]

17. Ning, D.Z.; Wang, R.Q.; Zhang, C.W. Numerical simulation of a dual-chamber oscillating water column wave energy converter. Sustainability 2017, 9, 1599. [CrossRef]

18. Ulazia, A.; Penalba, M.; Ibarra-Berastegui, G.; Ringwood, J. Wave energy trends over the Bay of Biscay and the consequences for wave energy converters. Energy 2017, 141, 624-634. [CrossRef]

19. Tsai, C.P.; Ko, C.H.; Chen, Y.C. Investigation on performance of a modified breakwater-integrated OWC wave energy converter. Sustainability 2018, 10, 643. [CrossRef]

20. Venugopal, V.; Nemalidinne, R.; Vögler, A. Numerical modelling of wave energy resources and assessment of wave energy extraction by large scale wave farms. Ocean Coast. Manag. 2017, 147, 37-48. [CrossRef]

21. Luczko, E.; Robertson, B.; Bailey, H.; Hiles, C.; Buckham, B. Representing non-linear wave energy converters in coastal wave models. Renew. Energy 2018, 118, 376-385. [CrossRef]

22. Spengler, J.J. Vertical integration and antitrust policy. J. Political Econ. 1950, 58, 347-352. [CrossRef]

23. Feng, X.H.; Moon, I.K.; Ryu, K.Y. Revenue-sharing contracts in an N-stage supply chain with reliability considerations. Int. J. Prod. Econ. 2014, 147, 20-29. [CrossRef]

24. Feng, X.H.; Moon, I.K.; Ryu, K.Y. Supply chain coordination under budget constraints. Comput. Ind. Eng. 2015, 88, 487-500. [CrossRef]

25. Moon, I.K.; Feng, X.H. Supply chain coordination with a single supplier and multiple retailers considering customer arrival times and route selection. Transp. Res. Part E 2017, 106, 78-97. [CrossRef] 
26. Shi, W.M.; Wang, G.G.; Zhao, X.; Feng, X.H.; Wu, J. Price determination in the electrolytic aluminum industry: The role of electricity prices. Resour. Policy 2018. [CrossRef]

27. Uihlein, A.; Magagna, D. Wave and tidal current energy-A review of the current state of research beyond technology. Renew. Sustain. Energy Rev. 2016, 58, 1070-1081. [CrossRef]

28. Scarf, H. A min-max solution of an inventory problem. In Studies in the Mathematical Theory of Inventory and Production; Arrow, K., Karlin, S., Scarf, H., Eds.; Stanford University Press: Palo Alto, CA, USA, 1958; pp. 201-209.

29. Gallego, G.; Moon, I.K. The distribution free newsboy problem: Review and extensions. J. Oper. Res. Soc. 1993, 44, 825-834. [CrossRef]

30. Medina-Lopez, E.; Allsop, N.W.H.; Dimakopoulos, A.; Bruce, T. Conjectures on the Failure of the OWC Breakwater at Mutriku. In Proceedings of the 2015 Coastal Structures and Solutions to Coastal Disasters Joint Conference, Boston, MA, USA, 9-11 September 2015.

31. Arena, F.; Romolo, A.; Malara, G.; Fiamma, V.; Laface, V. The First Full Operative U-OWC Plants in the Port of Civitavecchia. In Proceedings of the 36th International Conference on Ocean, Offshore and Arctic Engineering, Trondheim, Norway, 25-30 June 2017.

32. Contestabile, P.; Iuppa, C.; Di Lauro, E.; Cavallaro, L.; Andersen, L.T.; Vicinanza, D. Wave loadings acting on innovative rubble mound breakwater for overtopping wave energy conversion. Coast. Eng. 2017, 122, 60-74. [CrossRef]

33. Ruan, X.; Feng, X.H.; Pang, K. Development of port service network in OBOR via capacity sharing: An idea from Zhejiang province in China. Marit. Policy Manag. 2018, 45, 105-124. [CrossRef]

34. Azzellino, A.; Lanfredi, C.; Contestabile, P.; Ferrante, V.; Vicinanza, D. Strategic environmental assessment to evaluate WEC projects in the perspective of the environmental cost-benefit analysis. In Proceedings of the Twenty-First International Offshore and Polar Engineering Conference, Maui, HI, USA, 19-24 June 2011.

(C) 2018 by the authors. Licensee MDPI, Basel, Switzerland. This article is an open access article distributed under the terms and conditions of the Creative Commons Attribution (CC BY) license (http:/ / creativecommons.org/licenses/by/4.0/). 